\title{
Prevalence of Rifampicin Resistant Tuberculosis and its Associated Factors Among Patients at Lubaga Hospital.
}

\author{
Winnie Nakibonekaa,1,2 \\ ${ }^{a}$ Department of Health Sciences, University of Kisubi
}

\begin{abstract}
\end{abstract}

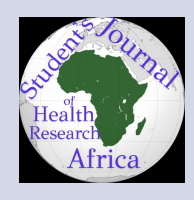

\section{Background: ${ }^{a}$}

Tuberculosis (TB) remains one of the world's leading causes of adult morbidity and mortality resulting in an estimated 8.8 million incident cases and 1.4 million deaths Up to $92 \%$ of the TB cases occur in low and middle-income countries with the sub-Saharan Africa region hosting nine of the highest TB incidence countries globally Uganda is ranked 16th among the 22 high burden countries. It is estimated that nearly 60,000 MDR- TB cases occur annually in the sub-Saharan region and these comprise $14 \%$ of the global burden of TB. In Uganda West Nile, the general prevalence of Mycobacterium tuberculosis is reported to be $20.2 \%$ and MDR-TB is $2.7 \%$

Methodology:

A cross-sectional descriptive study about the prevalence of rifampicin-resistant tuberculosis and its associated factors among patients was conducted on 384 TB patients at Lubaga hospital. The patients were selected by simple random sampling and data was collected by the use of a structured questionnaire and analysis were done using SPSS version 17.

\section{Results:}

The prevalence of rifampicin resistance according to this study's findings was $10 \%$. The predisposing factors to rifampicin resistance were cigarette smoking $(P$-Value $=0.001)$, history of prolonged stay with a TB infected patient, $(P$-Value $=0.001)$, and history of a previously treated episode of TB among the study respondents ( $P$-Value $=0.001)$.

\section{Conclusion and recommendations}

The government of Uganda needs to carry out more intensified mass sensitization of people about the dangers of cigarette smoking, particularly to HIV infected individuals. In the same line of sensitization, people need to be continuously reminded by the ministry of health about the signs and symptoms of TB so that community members can identify suspects and refer them for specialized diagnosis and management such that delayed detection of the disease is minimized which will also reduce on rifampicin resistance.

\footnotetext{
email: wnachie5@gmail.com

recieved: 16th/12/2020 accepted:

20th/12/2020 journal of microbiology
}

\section{Background:}

Tuberculosis (TB) remains one of the world's leading causes of adult morbidity and mortality resulting in an estimated 8.8 million incident cases and 1.4 million deaths (Lukoye et al., 2013). Up to $92 \%$ of the TB cases occur in low and middle-income countries with the sub-Saharan Africa region hosting nine of the highest TB incidence countries globally (WHO, 2011). Uganda is ranked 16th among the 22 high burden countries (NTLP, 2010). Treatment of 
tuberculosis lasts at least 8-months using a combination of first-line drugs: Isoniazid, Rifampicin, Pyrazinamide, Ethambutol, and Streptomycin. Rifampicin and Isoniazid both form an integral part of the initiation and continuation phase of antitubercular treatment regimens in all defined categories of patients (WHO, 2010).

Rifampicin (RMP) is associated with the lowest occurrence of resistance against tubercle bacilli (Mukinda et al., 2010). It is estimated that nearly 60,000 MDR- TB cases occur annually in the subSaharan region and these comprise $14 \%$ of the global burden of TB (WHO, 2010). Rifampicinmonoresistant TB (RMR-TB) has been noted as a problem in the United States, particularly in HIVinfected individuals (Sandman et al., 2000). A study in the Western Cape of South Africa by Mukinda et al., (2010) reported a $12 \%$ prevalence of RMR-TB and found alcohol, HIV co-infection, and other factors as predisposing factors to resistance. Studies done in some sub-Sahara African countries indicate low rates of MDR-TB defined as resistance to at least INH and RIF among new patients of TB. The prevalence of MDR-TB was $1.4 \%$ in Burundi, $1.2 \%$ in Tanzania, 2.6\% in the Gambia, and 3.4\% in Mozambique (WHO, 2010). In Rwanda, the prevalence of MDR-TB was $3.9 \%$ (Umubweyi, 2011).

A study by Jones-Lopez et al., (2011) in Mulago Hospital on TB patients reported a $23 \%$ prevalence of MDR-TB and a $1 \%$ prevalence of Rifampicin Mono resistance. Lukoye et al., (2011), in a Kampala survey among new cases of $T B$, reported a prevalence of MDR Tuberculosis of $1.1 \%$ and rifampicin mono resistance of $0.8 \%$. They however found no association between MDR and HIV co-infection. A survey done by Lukoye et al., (2011) in Uganda among old and new cases of TB reported a prevalence of rifampicin resistance of $0.4 \%$ among 1209 new TB cases and a rifampicin resistance of $23 \%$ among previously treated cases. All Rifampicin resistant cases were also Multi-drug resistant. Rifampicin plays a prominent role in TB treatment as one of the first-line TB drugs and this drug mustn't develop resistance because of the limited treatment alternatives available. Furthermore, the detection of rifampicin resistance is important in directing clinicians in the making of informed decisions. Several factors influence the development of TB resistance which can be due to the patient adherence, the treatment regimen itself, or pre-treatment factors. In 2001, the MoH through the National Tu- berculosis and Leprosy Program formally adopted the community-based TB Care (CBTBC) strategy to address the TB challenges in the country. Much as chronic cases can be detected using sputum smears and resistance made by microbiological cultures, there is a need to increase the case detection rates of new and old resistance cases if TB is to be put under control. Scaling up the use of the Gen expert which is a faster, accurate, and robust method needs to be done expeditiously so that the burden of MDR-TB does not reverse gains made in both TB and the HIV fight.

Drug resistance among tuberculosis patients is a major and emerging threat to its control and treatment both globally and in Uganda and this threatens to reverse the gains made so far in the fight against tuberculosis. TB had a death rate of 5.3\% and in 2007 it claimed 9.3 million lives a good number who were drug-resistant (WHO, 2008). No national study has been done on TB drug resistance so far. However, a study done in some parts of Uganda reported a Rifampicin resistance prevalence of $0.8 \%$ while a study among 214 admitted patients at Mulago National referral hospital in 2000 reported a rifampicin prevalence of 1.4\% (Lopez et al., 2011 ). While these rates appear low, concern has to be raised about the reducing cure rates of TB by rifampicin and isoniazid as reported in South Africa which is no different from Uganda thus highlighting the need for closer scrutiny of these rates (Wright, 2009).

A recent study by Nshizirungu et al.,(2020) reported The general prevalence of Mycobacterium tuberculosis is $20.2 \%$ and MDR-TB is $2.7 \%$ in west Nile refugee camps. No drug resistance study has been done among Lubaga hospital TB patients. There needs to be a more comprehensive study about TB drug resistance and particularly about rifampicin since this drug is a surrogate marker of MDR-TB. Relapses seem to be on the rise in Lubaga hospital and cure rates are not exactly known. The need for more elucidation about the resistance of TB primary drugs needs to be done to aid the better management of all categories of TB patients in Lubaga hospital.

\section{Study site \\ 2 METHODOLOGY}

The study was carried out in Lubaga hospital. The hospital is located on Rubaga hill just adja- 
cent to Lubaga cathedral, about $5 \mathrm{~km}$ from the city Centre. Lubaga hospital is one of the oldest hospitals in Uganda having been founded in 1899, over 100years ago. It is the second oldest hospital in the country and has offered health care to millions of people during its long history of existence. Over the years the hospital has built a reputation as a provider of affordable health care services and therefore has continued to attract and treat people of mainly mid-level and low-level status. The hospital serves a low-income community of an official catchment area of 130,000 people in urban Kampala -Lubaga Division (KCCA data).

Lubaga Hospital is a 275 bed, private-not-forprofit hospital of the Archdiocese of Kampala. It provides medical services in pediatrics, maternity/gynecology, internal medicine, surgery, Public Health, and HIV Care and Treatment.

In October 2012 the Board decided that the name of the hospital should be changed: from previously Rubaga Hospital to Lubaga Hospital. The Board also clarified that the full name of the hospital is now"Uganda Martyrs Hospital Lubaga."

\section{Study design}

This was a cross-sectional descriptive study that enrolled clients who were on TB treatment.

\section{Study population}

The study population comprised of all TB patients accessing services from Lubaga hospital during the time of the study.

\section{Sample size determination}

The sample size was determined following the formula Kish and Leslie (1965)

$\mathrm{N}=\mathrm{Z} 2 \mathrm{PQd} 2$

Where: $\mathrm{n}=$ Sample size

$Z=$ Standard normal deviation usually set at $95 \%$ (1.96)

$\mathrm{p}=$ Prevalence. Using $50 \%$ as the prevalence since the prevalence of Rifampicin resistant TB is not known (0.5)

$\mathrm{Q}=(1-\mathrm{p})=(1-0.5)=0.5$

$d=$ Standard error allowed in the study set at, $5 \%$

$=(0.05)$

Therefore $\mathrm{N}=1.9620 .5 \times 0.50 .052$

$=384$

\section{TB clients were enrolled into} the study

Selection criteria

Sampling method
Study participants were selected using a simple random sampling method. For this research, 384 papers had the words "yes" written on them and another 384papers had the words "no" written on them. The papers were carefully rolled in approximately similar ways before being shuffled in a cup. The TB clients were then asked to each pick a paper from the cup and only those picking the paper with the words "yes" were selected into the study. In the selection process, papers were shuffled after every pick.

\section{Inclusion criteria}

Only TB patients at Lubaga hospital TB clinic who were attending the TB clinic during the period of the study were eligible for enrolment into the study and were recruited if they consented to take part in the study. For children, they were only enrolled upon the consent of their parents or caretakers.

\section{Exclusion criteria}

Non-TB patients plus the ones who refused to consent during the time of the study were excluded from the study.

\section{Data collection tool}

The instrument to be used for data collection was a structured questionnaire

Data collection procedure and management

The structured questionnaire was selfadministered for literate participants and interviewer-administered for illiterate clients. The questionnaire was reviewed to see if it was filled and all those questionnaires found to be partially filled in were handed back to their respective respondents for completion before re-submission to the researcher. One sputum specimen was also collected from the study participants and was analyzed by gene Xpert machine (See appendix IV).

\section{Data management and analysis}

Data collected was stored in a data master sheet and transferred to Microsoft excel. Data was kept with utmost security by the use of codes, passwords, and encryption.

Data was exported to SPSS for Windows version 17 and analyzed with the help of a statistician. Descriptive statistics were computed and presented in form of diagrams, measures of central tendency (especially the mean, mode, median), and measures of dispersion. The existence of any significant differences between patients' categories was investigated.

\section{Quality control}


Furthermore, temperature logs, maintenance logs of the machine, and routine maintenance were used. Laboratory controls were run and monitored during the study period.

\section{Ethical consideration}

The researcher sought permission from Lubaga hospital research committee to do the study. Information to be obtained from the respondents was treated with the utmost confidentiality. Study numbers but no names were used on questionnaires for data collection as a way of keeping the respondents' identity anonymous. Informed consent was also sought from each of the respondents before enrolling them into the study

\section{Dissemination of results}

Results of the study were compiled into a research report, copies of which were disseminated to Lubaga hospital and the faculty of Health sciences of University of kisubi such that the information can spread to all concerned people.

\section{RESULTS}

\section{Socio-Demographic Characteristics}

Figure 1: Distribution of the study respondents by their ages

Figure 2: Distribution of respondents by their gender

Figure 3: Distribution of respondents by their education status

Figure 4: Distribution of respondents by their occupations

\section{Prevalence of rifampicin-resistant TB among} patients in Lubaga hospital

Figure 5: Showing rifampicin resistance among the study respondents

Factors associated with Rifampicin resistance among TB patients in Lubaga hospital

bove shows that of the 24 patients who had been treated for TB before, 13 had rifampicin sensitive tubercle bacilli, 7 had rifampicin-resistant strains and for 4 respondents, this wasn't applicable. The table further shows that of the 360 respondents who had never been treated for TB before, 58 had rifampicin sensitive tubercle bacilli, 32 had rifampicin-resistant strains and for 270 , this was not applicable.

\section{P-Value $=0.438$}

bove shows that of the 6 respondents who had completed TB treatment before, 4 had rifampicin sensitive tubercle bacilli and 2 had rifampicin resistant tubercle bacilli strains. The table further shows that of the 18 respondents who hadn't completed the anti-TB treatment, 10 rifampicin sensitive tubercle bacilli, and 4 had rifampicin-resistant tubercle bacilli strains and to 18 respondents, this wasn't applicable.

\section{P-Value $=0.002$}

bove shows that of the 6 respondents who had ever had prolonged contact with a patient in their past, 2 had rifampicin sensitive tubercle bacilli, 3 had rifampicin-resistant tubercle bacilli and 1 had it not applicable. The table further shows that of the 378 respondents who had not had a prolonged stay with a TB patient in their past, 69had rifampicin sensitive tubercle bacilli, 36 had rifampicin-resistant tubercle bacilli and to 273 respondents, this was not applicable.

\section{P-Value $=0.001$}

bove shows that of the 15 respondents who were cigarette smokers, 8 had rifampicin-sensitive tubercle bacilli, 3 had rifampicin-resistant strains of tubercle bacilli and 4 had this as not applicable. The table further shows that of the 369 respondents who were not cigarette smokers, 63 had rifampicinsensitive bacilli, 36 had rifampicin-resistant strains of tubercle bacilli and for 270 respondents this was not applicable.

\section{P-Value $=0.001$}

bove shows that of the 24 respondents, who were consumers of alcohol, 14 had rifampicin sensitive tubercle bacilli, 6 had rifampicin-resistant strains of the tubercle bacilli and for 4 respondents this was not applicable. The table further shows that of the 360 respondents who were non-alcohol consumers, 57 had rifampicin-sensitive tubercle bacilli, 33had rifampicin-resistant strains of tubercle bacilli and to the 270 respondents this was not applicable.

\section{P-Value $=0.116$}

above shows that of the 9 respondents, who were users of Marijuana or Cocaine or Mairungi, 4 had rifampicin sensitive tubercle bacilli, 1 had rifampicin resistance and to the remaining 4 , it was not applicable. The table also shows that of the 275 respondents, who were not using Marijuana or Cocaine or Mairungi, 67 had rifampicin sensitive tubercle bacilli, 38 had rifampicin-resistant tubercle bacilli, and 270 , this was not applicable.

P-Value $=0.256$

above shows that of the 287 respondents who were HIV positive, 50 had rifampicin sensitive tubercle bacilli, 33 had rifampicin resistance and 204 


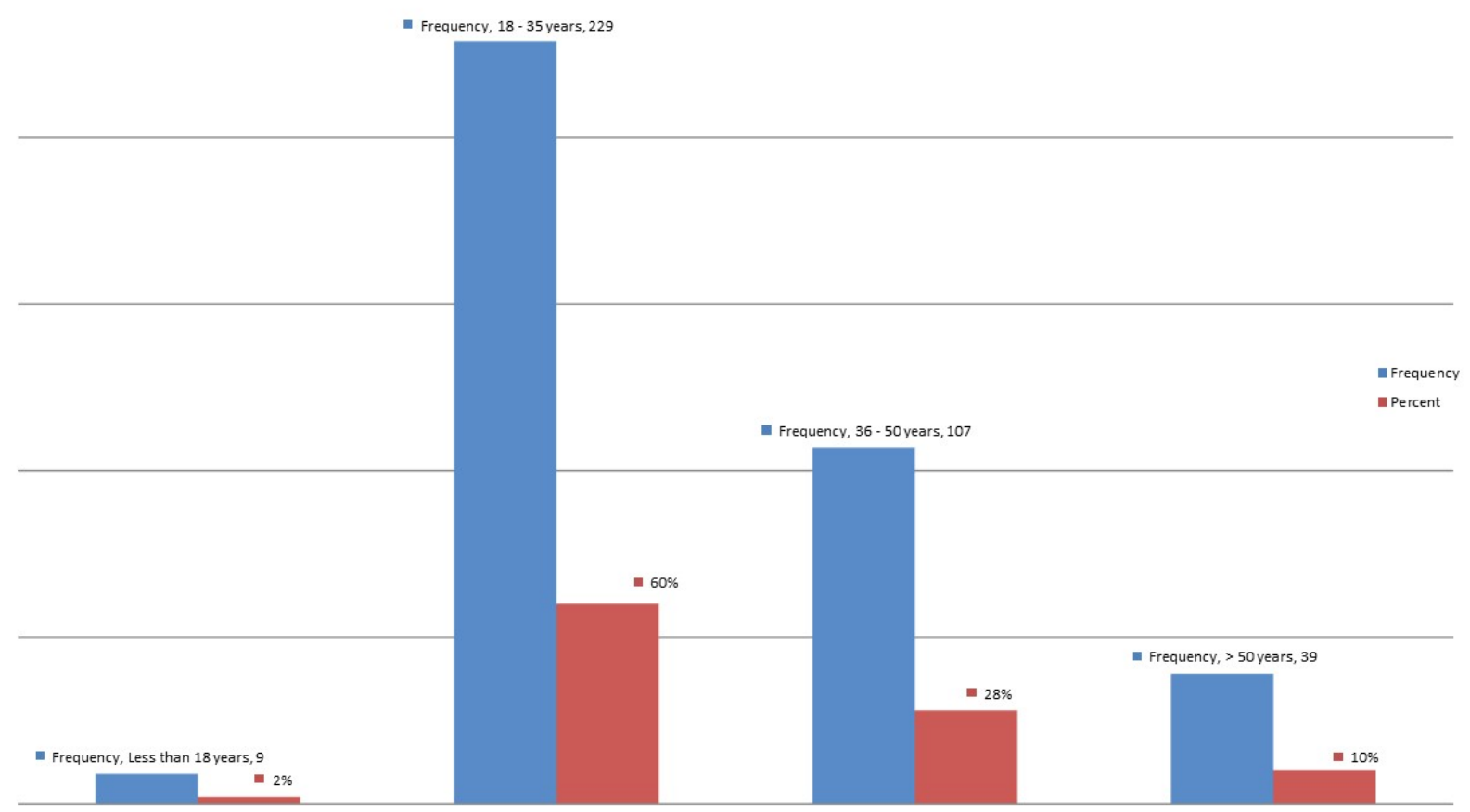

Chart 1. above shows that $229(60 \%)$ of the respondents were aged 18 to 35years, 107 (28\%) were 36 to 50 years, 39 $(10 \%)$ were above $50 y e a r s$ and $9(2 \%)$ were less than $18 y e a r s$.
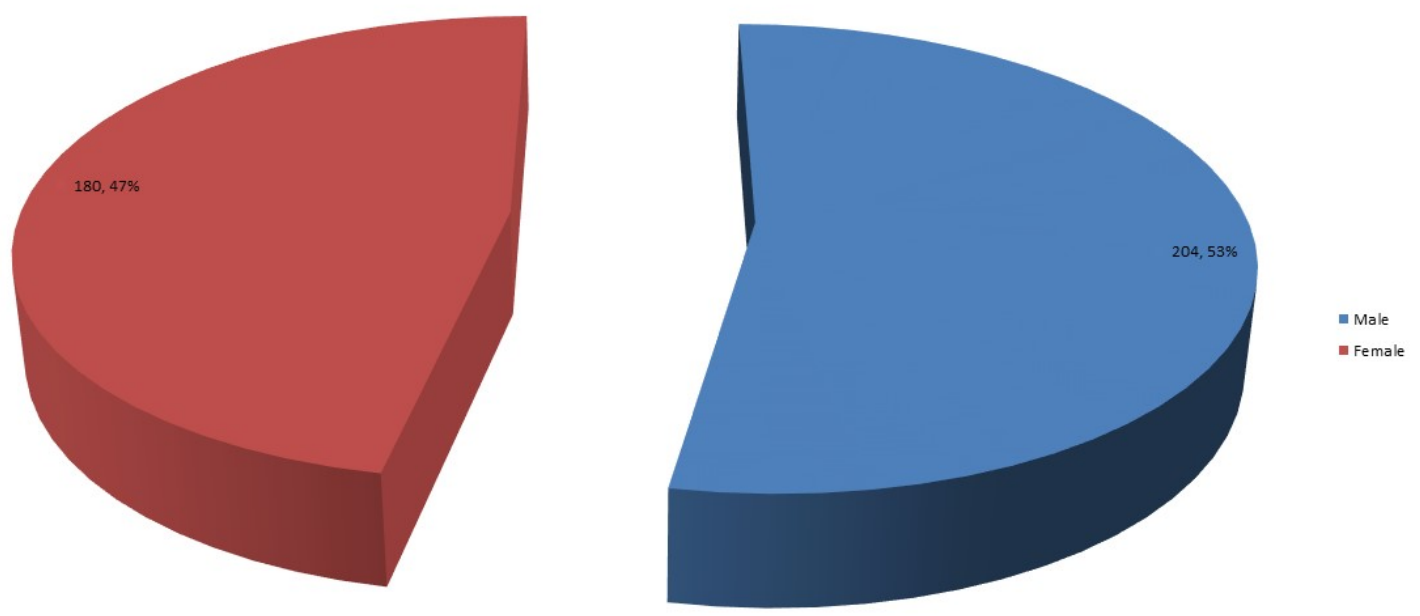

Chart 2. above shows that 204 (53\%) of the respondents were male and 180 (47\%) were females. 


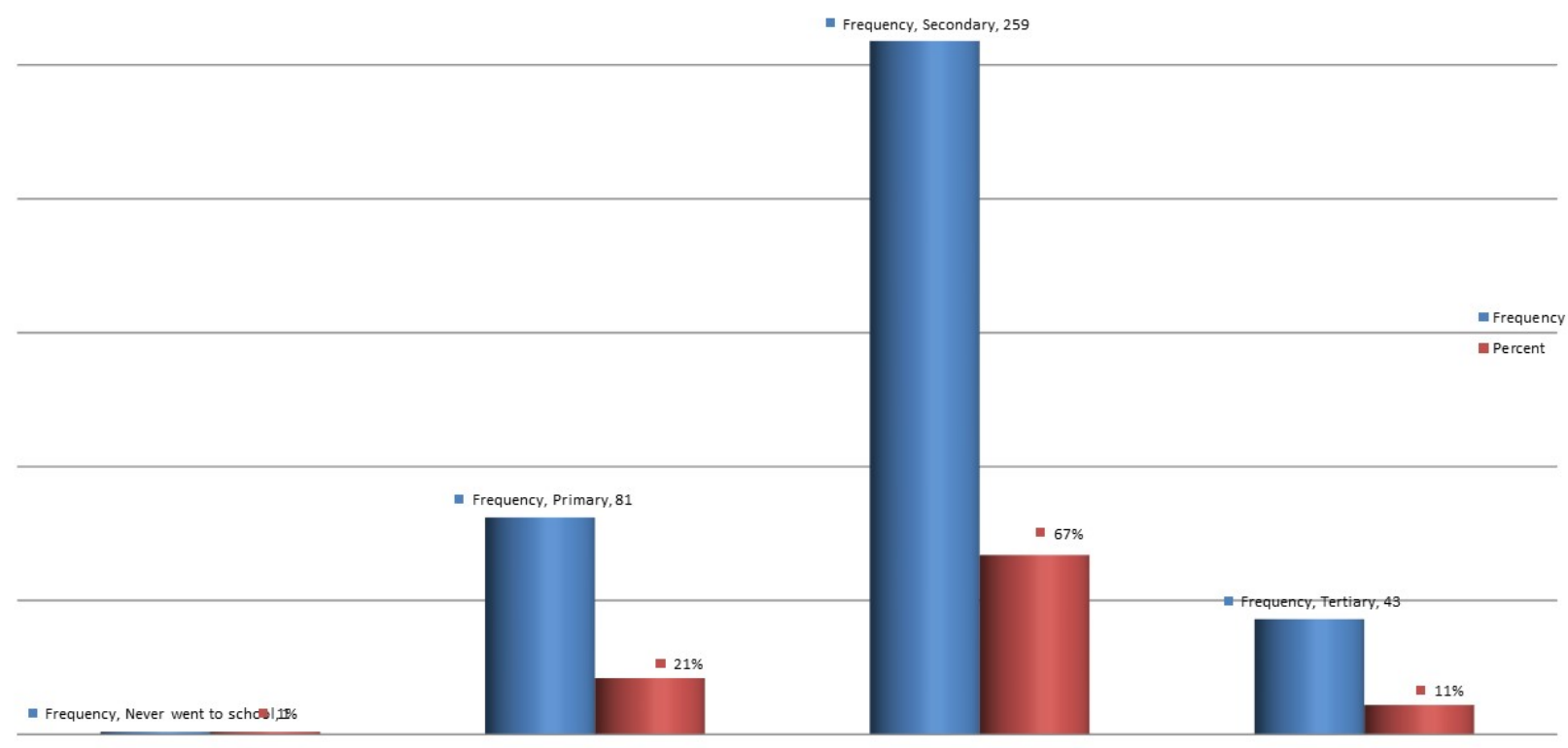

Chart 3. above shows that 259 (67\%) of the respondents had gone up to secondary school for their education, 81 (21\%) had stopped in primary school, $43(11 \%)$ had attained a tertiary level of education and $1(1 \%)$ was illiterate.

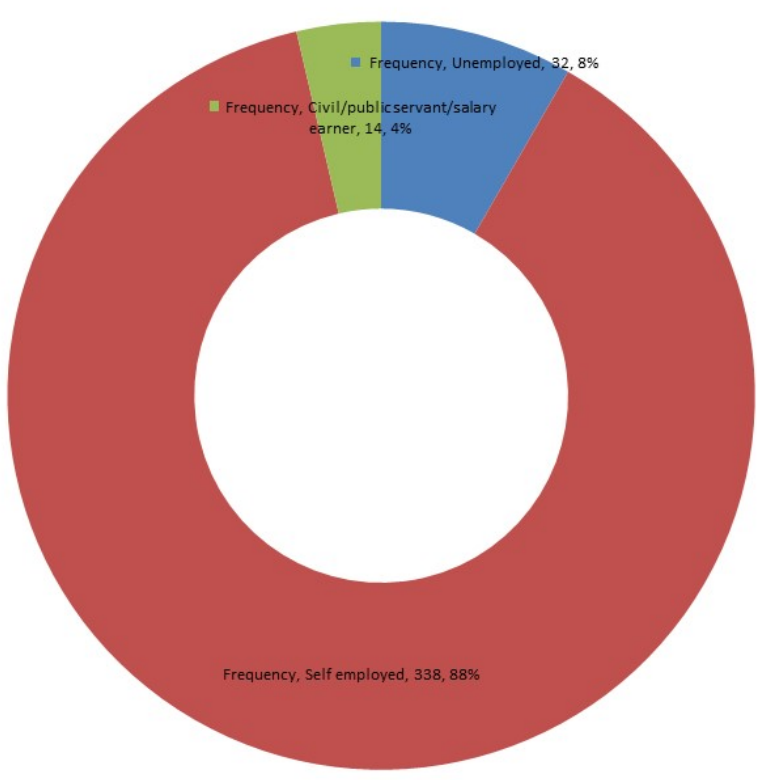

- Unemployed

- Self employed

- Civil/public servant/salary earner

Chart 4. above shows that by occupation, 338 (88\%) of the respondents were self-employed, 32 (8\%) were unemployed and 14 (4\%) were Civil/public servants/salary earners. 


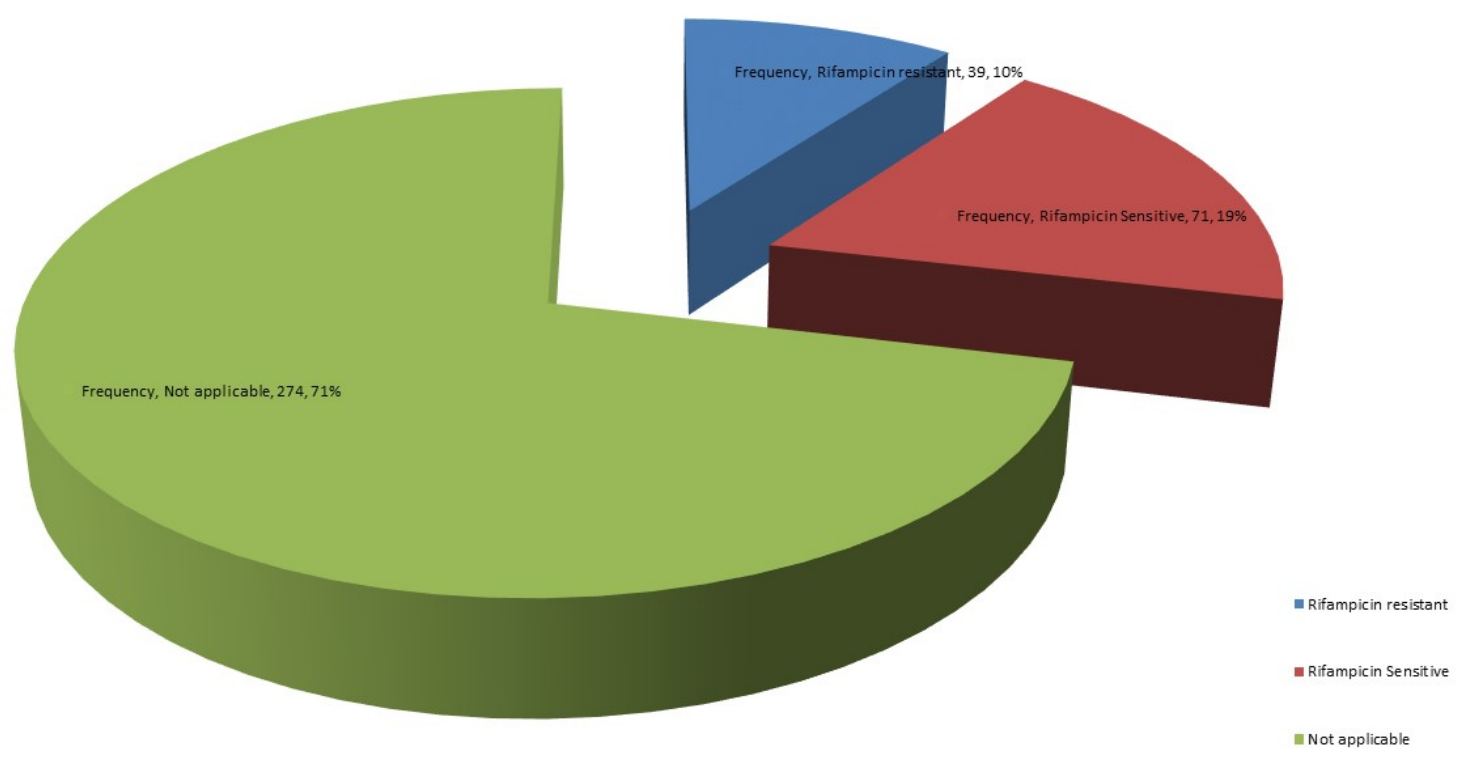

Chart 5. above shows that 39 (10\%) of the respondents had rifampicin-resistant strains of Mycobacterium tuberculosis, 71 (19\%) had sensitive strains and 274 (71\%) of the respondents had this non-applicable.

Table 1. History of previous TB treatment of the study respondents related to their rifampicin sensitivity status

\begin{tabular}{lllll}
\hline & & \multicolumn{2}{l}{ Have you been treated for TB before? } & Total \\
& Sensitive & Yes & No & 71 \\
& Resistant & 73 & 58 & 39 \\
& Not Applicable & 4 & 32 & 274 \\
Total & & 24 & 270 & 384 \\
\hline
\end{tabular}

Table 2. Status of completion of treatment among previously TB positive patients related to their rifampicin sensitivity status

\begin{tabular}{|c|c|c|c|}
\hline & \multicolumn{2}{|c|}{$\begin{array}{l}\text { If yes to question e) above, did you com- } \\
\text { plete treatment }\end{array}$} & \multirow[t]{2}{*}{ Total } \\
\hline & Yes & No & \\
\hline Sensitive & 4 & 10 & 14 \\
\hline Resistant & 2 & 4 & 6 \\
\hline Not Applicable & 0 & 4 & 4 \\
\hline Total & 6 & 18 & 24 \\
\hline
\end{tabular}


Table 3. History of prolonged contact with TB patient in respondent's history related to their rifampicin sensitivity.

\begin{tabular}{clll}
\hline & Have & Total \\
& you ever & \\
stayed & & \\
& with a TB & \\
patient or & \\
& treated & \\
& one & & \\
& Yeas & No & \\
Sensitive & 2 & 69 & 71 \\
Resistant & 3 & 36 & 39 \\
Not Applicable & 1 & 273 & 274 \\
Total & 6 & 378 & 384 \\
\hline
\end{tabular}

Table 4. Smoking status of respondents related to their rifampicin sensitivity status

\begin{tabular}{clll}
\hline Count & $\begin{array}{l}\text { Do you } \\
\text { smoke } \\
\text { cigarettes }\end{array}$ & Total \\
& $\begin{array}{l}\text { Yes } \\
\text { No }\end{array}$ & \\
Sensitive & 8 & 63 & 71 \\
Resistant & 3 & 36 & 39 \\
Not Applicable & 4 & 270 & 274 \\
Total & 15 & 369 & 384 \\
\hline
\end{tabular}

Table 5. Alcohol consumption of respondents related to their rifampicin sensitivity status.

\begin{tabular}{clll}
\hline Count & \multicolumn{2}{l}{$\begin{array}{l}\text { Do you } \\
\text { drink } \\
\text { alcohol }\end{array}$} & Total \\
& Yes & No & \\
Sensitive & 14 & 57 & 71 \\
Resistant & 6 & 33 & 39 \\
Not Applicable & 4 & 270 & 274 \\
Total & 24 & 360 & 384 \\
\hline
\end{tabular}

Table 6. Marijuana or Cocaine orMairungi use among respondents related to their rifampicin sensitivity status.

\begin{tabular}{clll}
\hline \multirow{2}{*}{ Count } & $\begin{array}{l}\text { Do you } \\
\text { use }\end{array}$ & Mar- Total \\
& ijuana & \\
& or & Co- & \\
& caine or & \\
& Mairungi & \\
& Yes & No & \\
Sensitive & 4 & 67 & 71 \\
Resistant & 1 & 38 & 39 \\
Not Applicable & 4 & 270 & 274 \\
Total & 9 & 375 & 384 \\
\hline
\end{tabular}


Table 7. HIV status of the respondents related to their rifampicin sensitivity status.

\begin{tabular}{clll}
\hline Count & $\begin{array}{l}\text { What is your HIV } \\
\text { status? }\end{array}$ & Total \\
& Positive & Negative & \\
Sensitive & 50 & 21 & 71 \\
Resistant & 33 & 6 & 39 \\
Not Applicable & 204 & 70 & 274 \\
Total & 287 & 97 & 384 \\
\hline
\end{tabular}

had the question as not applicable. The table also shows that of the 97respondents who were HIV negative, 21 had rifampicin sensitive tubercle bacilli, 6 had rifampicin-resistant bacilli and to 70 respondents, it was not applicable.

\section{DISCUSSION OF RESULTS, CONCLUSIONS, AND RECOMMENDATIONS}

\section{Socio-Demographic Characteristics of the study respondents}

It was revealed that the majority, $229(60 \%)$ of the respondents in this study were aged 18 to 35years, followed by 107 (28\%) who were 36 to $50 y e a r s$ old, then by $39(10 \%)$ who were above 50years and lastly by $9(2 \%)$ respondents who were less than 18years old (Figure 1).

Slightly more than half, 204 (53\%) of the respondents were male and 180 (47\%) were females (Figure 2) whereas, by educational status, slightly more than two thirds, 259 (67\%) of the respondents had gone up to secondary school, about one fifth, 81 (21\%) had stopped in primary school, about onetenth 43 (11\%) had attained a tertiary level of education and $1(1 \%)$ were illiterate (Figure 3 ).

By occupation, $338(88 \%)$ of the respondents were self-employed, 32 (8\%) were unemployed and 14 (4\%) were Civil/public servant's/salary earners (Figure 4).

\section{Prevalence of rifampicin-resistant TB among patients in Lubaga hospital}

Up to $10 \%$ of the respondents had rifampicinresistant strains of Mycobacterium tuberculosis and this reveals a prevalence of rifampicin resistance of $10 \%$. This finding is a little higher than the prevalence of rifampicin mono-resistant Tuberculosis of 3.4\% reported in a study by Teshome et al., (2015). The prevalence finding of rifampicin resistance of
3.9\% in Rwanda and 2.7\% in Tanzania is also lower than this study's prevalence of $10 \%$ reported by (Kibiki, 2007).

Some studies done by Bazira et al., (2011), reported prevalence of $5.6 \%$ and in other Kampala studies which were also lower than this study's prevalence of rifampicin resistance of $10 \%$.

This study's prevalence finding of $10 \%$ is however lower than the prevalence of rifampicin resistance of $46 \%$ reported in an Iranian study by Fasih et al., (2012).

Factors associated with Rifampicin resistance among TB patients in Lubaga hospital

It was discovered in this study that out of the 24 patients who had been treated for TB before, 13 had rifampicin-sensitive tubercle bacilli and 7 had rifampicin-resistant strains (Table 1; P-Value = 0.001 ). This shows that a strong association existed between the two variables and as such makes the finding to be similar to that of Mendez et al., (1998), who reported that previous treatment was widely recognized as inducing multidrug resistance of $M$. tuberculosis.

Of the 6 respondents who had completed TB treatment before the current relapse, 4 had rifampicin-sensitive tubercle bacilli and 2 had rifampicin-resistant tubercle bacilli strains (Table 2., P-Value $=0.438$ ). Based on the $p$-value, there was no significant statistical association between completion of treatment and sensitivity and makes this finding contrary to the observation made by (WHO, 2007) that non-adherence is one of the reasons for the failure of achievement of the global treatment success rates of TB by Uganda.

In this study, 6 respondents had prolonged contact with a patient in their past, and out of these, 2 had rifampicin sensitive tubercle bacilli, 3 had rifampicin-resistant tubercle bacilli, P-Value $=0.001$ (Table 3). It is possible that there was delayed recognition of TB in the patients they had lived with 
such that those patients had developed rifampicinresistant strains which they had passed on to this study's respondents who in turn developed rifampicin resistance which relates with the findings of Pablo-Méndez A (1998).

There was a total of 15 respondents who were cigarette smokers, and of these, 8 had rifampicinsensitive tubercle bacilli whereas 3 had rifampicinresistant strains of the tubercle bacilli (Table 4, PValue $=0.001$ ). This implies that cigarette smoking increased one's chances of getting resistance to rifampicin which is in line with the findings of Van et al., (2010) who in a study carried out in Cape Town, reported that tobacco smoking causes bronchitis, chronic obstructive pulmonary disease (COPD) and chronic pulmonary disability which are risk factors for MDR-TB. This implies that people who smoke cigarettes have nearly twice the risk of TB drug resistance than non-smokers.

According to this study, 24 respondents were consumers of alcohol and out of these, 14 had rifampicin-sensitive tubercle bacilli and 6 had rifampicin-resistant strains of the tubercle bacilli (Table 5; P-Value $=0.116$ ). Based on this study's p-value, alcohol consumption was not statistically associated with rifampicin resistance.

Among the 9 Marijuana or Cocaine or Mairungi users in this study, 4 of them had rifampicinsensitive tubercle bacilli whereas 1 had rifampicin resistance (Table 6 , P-Value $=0.116$ ). This shows that there was no significant association between these drugs and rifampicin resistance.

Of the 287 respondents in this study who were HIV positive, 50 had rifampicin-sensitive tubercle bacilli and 33 had rifampicin-resistant strains (Table 7). Though by numbers there seems to be a variation between rifampicin-sensitive tubercle bacilli and rifampicin-resistant strains wasn't statistically significant ( $P$-Value $=0.256$ ). This is contrary to the findings of Bazira et al., (2011), who reported TB treatment resistance as linked to HIV.

\section{Conclusions}

The prevalence of rifampicin resistance according to this study's findings was $10 \%$.

The predisposing factors to rifampicin resistance were cigarette smoking $(P$-Value $=0.001)$, history of prolonged stay with a TB infected patient, (PValue $=0.001)$, and history of a previously treated episode of TB among the study respondents ( $P$ Value $=0.001$ ).

\section{Recommendations}

The government of Uganda needs to carry out more intensified mass sensitization of people about the dangers of cigarette smoking, particularly to HIV infected individuals.

In the same line of sensitization, people need to be continuously reminded by the ministry of health about the signs and symptoms of TB so that community members can identify suspects and refer them for specialized diagnosis and management such that delayed detection of the disease is minimized which will also reduce on rifampicin resistance. It will also minimize the exposure of people living with infected individuals.

\section{List of Abbreviations and Acronyms}

AIDS: Acquired Immune Deficiency Syndrome

ART: Antiretroviral Therapy

CT: Cycle Threshold

DNA: Deoxy Ribonucleic Acid

DST: Drug Susceptibility Testing

HAART: Highly Active Anti-retroviral Therapy

HIV: Human Immuno-deficiency Virus

INH: Isoniazid

LPA: Line Probe Assay

MDR: Multi- drug-resistant

$\mathrm{MoH}$ : Ministry of Health

MTB: Mycobacteria Tuberculosis

MTC: Mycobacteria Tuberculosis Complex

NTLP: National Tuberculosis and Leprosy Programme

PCR: Polymerase Chain Reaction

RIF: Rifampicin or its derivatives such as rifabutin

RIFR: Rifampicin Resistant

RMR: RifampicinMonoresistant Strain

RNA: Ribonucleic Acid

RT: $\quad$ Real Time

TB: Tuberculosis

WHO: World Health Organisation

\section{Acknowledgement}

I would like to acknowledge my supervisor Mr. Kennedy Charles, all my lecturers and classmates of 14 DMLT. 
I would like to thank the laboratory manager of Lubaga hospital laboratory and all the laboratory staff of Lubaga hospital laboratory for their time and support. May the Almighty God reward them abundantly.

\section{References:}

1) Bazira, J., Asiimwe, B. B., Joloba, M. L., Bwanga, F., \& Matee, M. I. (2011). Mycobacterium tuberculosis spoligotypes and drug susceptibility pattern of isolates from tuberculosis patients in South-Western Uganda. BMC infectious diseases, 11, 81.

https://doi.org/10.1186/1471-2334-11-81

PMid:21453482 PMCid:PMC3100262

2) Fasih N, Rafiq Y, Jabeen K and Hasan R (2012). High Isoniazid Resistance Rates in Rifampicin Susceptible Mycobacterium tuberculosis Pulmonary Isolates from Pakistan. PLoS ONE 7(11): e50551.

https://doi.org/10.1371/journal.pone.0050551 PMid:23226311 PMCid:PMC3511527

3) Jones-Lopez EC, Ayakaka I, Levin J, Reilly N,Mumbowa F.,Dryden-Peterson S, Nyakoojo G, Fennelly K, Temple B, Nakubulwa S, Joloba ML, Okwera $A$, Eisenach KD, McNerney R, Elliott AM, Ellner JJ, Smith PG \& Mugerwa RD(2011). Effectiveness of the standard WHO recommended retreatment regimen (category II) for tuberculosis in Kampala, Uganda: a prospective cohort study. PLoS Med,8(3):e1000427.

https://doi.org/10.1371/journal.pmed.1000427 PMid:21423586 PMCid:PMC3058098

4) Kibiki G, Mulder B, Dolmans W, de Beer J, Boeree $M$, Sam $N$, van Soolingen $D$, Sola $C$ \& van der Zanden A. M.(2007). Tuberculosis genotypic diversity and drug susceptibility pattern in HIVinfected and non-HIV-infected patients in northern Tanzania.BMC Microbial. 2007; 7:51 https://doi .org/10.1186/1471-2180-7-51 PMid:17540031 PMCid:PMC1913919

5) Lukoye D, Adatu F, Musisi K, Kasule GW, Were W, \& Odeke R, (2013) Anti-Tuberculosis Drug Resistance among New and Previously Treated Sputum smear-positive Tuberculosis Patients in Uganda: Results of the First National Survey. PLOS ONE 8(8): e70763

https://doi.org/10.1371/journal.pone.0070763 PMid:23936467 PMCid:PMC3731251

6) Mesfin Worku Hordofa, Teshome \& Befikadu Adela, (2015). Prevalence of Refampcin Mono Resistant Mycobacterium Tuberculosis Among Sus- pected Cases Attending at Yirgalem Hospital, Clinical Medicine Research. Vol. 4, No. 3, pp. 75-78.

https://doi.org/10.11648/j.cmr.20150403.13

7) Ministry of Health (2010), Manual of the National Tuberculosis and Leprosy Programme.

8) Mukinda, F. K., Theron, D., van der Spuy, G. D., Jacobson, K. R., Roscher, M., Streicher, E. M., Musekiwa, A., Coetzee, G. J., Victor, T. C., Marais, B. J., Nachega, J. B., Warren, R. M., \& Schaaf, H. S. (2012). Rise in rifampicin-monoresistant tuberculosis in Western Cape, South Africa. The international journal of tuberculosis and lung disease: the official journal of the International Union against Tuberculosis and Lung Disease, 16(2), 196-202. htt ps://doi.org/10.5588/ijtld.11.0116 PMid:22236920 PMCid:PMC3712259

9) N.T.L Programme, (2010).Anti-Tuberculosis Drug Resistance in Kampala-Uganda Are Low and Not Associated, p. 1-210.

10) Nshizirungu, L.., Olet, D., Amulen, D.., Michael, O., Luwuna, P., \& Izale, W. (2020). The Prevalence and Risk Factors of Multi Drug Resistant Tuberculosisamong Refugees in The Resettlementcamps of Adjumani, Moyo and Yumbe Districtswest Nile Region: pMDRTB. Student's Journal of Health Research Africa, 1(12), 14. https://doi.org/10.51168/sj hrafrica.v1i12.7

11) Pablo-Mendez, A., \& Laszlo, A. (1998). Global surveillance for antituberculosis drug resistance.The New England Journal of Medicine, 381641-381649.

12) Umubyeyi A, Shamputa IC, Rigouts $L$, DeviseA, Struelens M da Portaels F (2007.) Evidence of 'amplifier effect' in pulmonary multidrug-resistant tuberculosis: report of three cases. International Journal Infectious Diseases.Volume 11 pg508-512.

https://doi.org/10.1016/j.ijid.2007.01.009

PMid:17376726

13) Van Rie, A., L. Page-Shipp, L. Scott, I. Sanne, and W. Stevens (2010.) Xpert ${ }^{\circledR}$ MTB/RIF for point-of care diagnosis of TB in high-HIV burden, resource limited countries: hype or hope? Expert Review of Molecular Diagnosis. 10:937-946.

https://doi.org/10.1586/erm.10.67

PMid:20964612

14) WHO (2007) Global tuberculosis report: Uganda. WHO report: 145-147.

15) WHO, (2010) Treatment of Tuberculosis Guidelines 2010, in Treatment of Tuberculosis Guidelines. 2010, World Health Organization: Geneva. 
16) World Health Organization. (2011). Policy statement: automated real-time nucleic acid amplification technology for rapid and simultaneous detection of tuberculosis and rifampicin resistance: Xpert MTB/RIF system. World Health Organization, Geneva, Switzerland. 